\title{
Karakterisasi Dua Dimensi Difuser MLS (Maximum Length Squence) dengan Model 10101010 yang Terbuat dari Limbah Kertas dan Bahan Kayu
}

\author{
Keysha Wellviestu Zakri, Melania Suweni Muntini, dan Susilo Indrawati* \\ Jurusan Fisika, Fakultas Matematika dan Ilmu Pengetahuan Alam, \\ Institut Teknologi Sepuluh Nopember (ITS), Kampus ITS Sukolilo, Surabaya 60111
}

Intisari

\begin{abstract}
Masalah umum yang terjadi di dalam ruangan tertutup / auditorium adalah gema. Masalah gema dapat diminimalkan menggunakan bahan menyerap, tetapi menggunakan bahan ini bisa memberikan masalah lain yaitu distribusi suara yang tidak sama di dalam ruangan. Menggunakan diffuser adalah salah satu pilihan yang tepat untuk memecahkan masalah ini, karena selain dapat men-difuse suara, diffuser tidak mengurangi energi suara dalam ruangan. Penelitian ini dilakukan untuk mempelajari tentang MLS (Maximum Length Sequence) diffuser jenis 10101010 yang terbuat dari limbah kertas dan bahan kayu. Berdasarkan hasil penelitian, pola difus antara diffeser dari limbah kertas dan bahan kayu tidak tenang berbeda. Perbedaan signifikan adalah tingkat tekanan suara yang disebarkan oleh limbah kertas lebih rendah dari bahan berbasis kayu. Hasil ini bisa terjadi karena bahan berbasis limbah kertas tidak hanya meredakan suara yang masuk, tetapi juga bisa menyerap sebagian, karena karakteristik ini, jenis bahan disebut difsorber (diffuser dan bahan penyerap)
\end{abstract}

\begin{abstract}
The common problem which occurred inside closed room/auditorium is echo. The echo problem could be minimize using absorbing material, but using this material could lend to another problem, which is the sound distribution is not equal inside the room. Using diffuser is one of the correct choice to solved this problem, because beside could difuse the sound, diffuser does not reduce the sound energy inside the room. This experiment is conducted to study about MLS (Maximum Length Sequence) diffuser type 10101010 which made of waste paper and wood material. Based on the experiment result, the diffuse pattern between diffeser from waste paper and wood material is not quietly different. The significant difference is the sound pressurelevel which diffused by waste paper is lower than the wood based material. This result could be happen because the waste paper based material is not only diffuse the incoming sound, but also could absorb some of it, because of this characteristic, this kind of material is called difsorber (diffuser and absorber material).
\end{abstract}

KATA KUNCI: diffuser, diffuse coefficient, SPL (Sound Pressure Level), difsorber

\section{PENDAHULUAN}

Perkembangan ilmu dan teknologi berkembang sangat cepat, tak terkecuali perkembangan di bidang akustika ruangan dan bangunan. Dalam hal ini khususnya ruang auditorium. Ruang auditorium banyak digunakan untuk keperluan meeting, rapat besar, konser, konferensi dan seminar. Sering kali para pengguna ruang auditorium mengeluh mengenai kenyamanan pendengaran. Hal itu menyebabkan pembaharuan teknologi desain dari ruang auditorium itu sendiri sangat dibutuhkan. Karakter suatu ruang auditorium yang bagus dapat dilihat dari bunyi yang dapat didengar dari seluruh ruangan secara merata dan memiliki waktu dengung yang sesuai untuk fungsi ruang.

Untuk mendapatkan karakter ruang auditorium yang bagus seringkali dilakukan dengan penambahan bahan reflektor

\footnotetext{
*E-MAIL: susilo_i@physics.its.ac.id
}

pada dinding, lantai dan langit-langit. Pemberian reflektor yang banyak membantu untuk mendistribusikan bunyi. Namun pemberian reflektor yang tidak sesuai menyebabkan waktu dengung yang tinggi dan tidak merata, sehingga pada ruang yang besar (Auditorium) akan menimbulkan gema. Gema dapat diatasi dengan absorber yaitu material akustik yang mampu menyerap energi bunyi. Namun pemberian absorber menyebabkan masalah semula ingin membuat ruangan terdistribusi merata tidak tercapai. Pemberian difuser merupakan salah satu alternatif yang bisa digunakan karena selain dapat menghamburkan bunyi juga tidak mengurangi energi bunyi, sehingga penggunaan difuser pada auditorium cocok untuk digunakan. Trevor j. Cox dan D'Antonio telah melakukan penelitian tentang difuser MLS (Maximum Length Sequence) yang dijelaskan dalam buku dan kumpulan makalah tahun 2009, "Acoustic Absorber and Diffusers (theory, design and application)". Saat ini perkembangan difuser terarah pada susunan difuser dan bahan pembuat difuser [1]. Pada penelitian sebelumnya [2,3], digunakan difuser $1 \mathrm{D}$ dari bahan kayu dan diperoleh nilai kefisien difusi 0,39. 


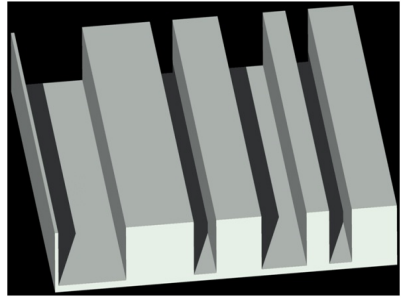

(a)

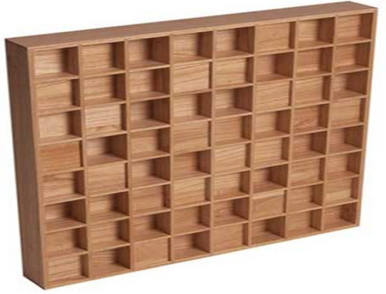

(b)
Gambar 1: Potongan diffuser MLS (a) satu dimensi; (b) dua dimensi.

Dalam penelitian ini dibuat difuser $2 \mathrm{D}$ dari bahan bubur kertas dan bahan kayu untuk mendapatkan nilai koefisien difusi dari difuser tersebut dan mengetahui perbedaan pola hamburan dari keduanya.

\section{Difuser}

Difuser merupakan material akustik yang sangat baik untuk penyerapan suara karena tidak menghilangkan energi suara, tetapi efektif untuk mengurangi gema dan pemantulan sementara ruangan masih tetap terdengar hidup. Karakter difuser dapat dinilai dari berbagai besaran seperti koefisien difusi (d), koefisien hamburan (s) dan pola hamburan difuser [4]. Maximum length sequence (MLS) 1 dimensi merupakan difuser yang terdiri dari permukaan dengan dua kedalaman yang berbeda yakni dengan kedalaman 0 dan 1. Angka satu (1) menunjukkan sebuah sumur, sedangkan angka nol (0) menunjukkan sebuah tonjolan. MLS 2 dimensi memiliki struktur yang sama dengan MLS 1D yaitu berstruktur kaku, dan namun terdiri dari sumur dengan kedalaman berbeda yang dipisahkan oleh dinding tipis [5]. Potongan diffuser MLS satu dan dua dimensi ditunjukkan Gambar 1.

\section{Sinyal}

Perubahan tekanan terhadap waktu dalam sistem salah satunya didekati dengan model sistem waktu diskrit. Dalam penelitian ini, pengolahan menggunakan transformasi Fourier bentuk sinyal diskrit (DFT) atau FFT (Fast Fourier Transform). Transformasi ini dapat digunakan untuk mengubah sinyal domain waktu $\mathrm{x}(\mathrm{n})$ menjadi domain frekuensi $\mathrm{x}(\mathrm{k})$. Persamaan DFT dituliskan sebagai:[6]

$$
x(k)=\sum_{n=0}^{N-1} x(n) e^{-j\left(\frac{2 \pi}{N} k\right) n}
$$

Invers DFT (IDFT) digunakan untuk mendapatkan kembali representasi sinyal diskrit dari domain frekuensi $\mathrm{x}(\mathrm{k})$ ke dalam domain waktu $x(n)$. Secara matematis dinyatakan dalam persamaan: [6]

$$
x(n)=\frac{1}{N} \sum_{k=0}^{N-1} x(k) e^{j 2 \pi\left(\frac{k}{N}\right) n}
$$

dengan $\mathrm{x}(\mathrm{k})=$ data dalam sinyal domain frekuensi, $\mathrm{x}(\mathrm{n})=$ data dalam sinyal domain waktu, $\mathrm{n}=$ data ke $(1,2,3), \mathrm{N}$ = banyaknya data.

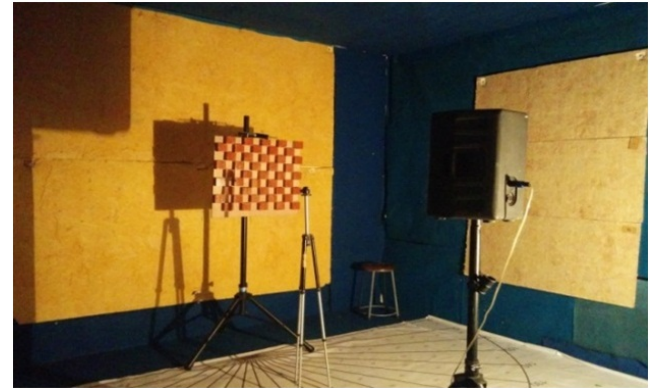

Gambar 2: Ruang uji penelitian.

\section{METODOLOGI PENELITIAN}

Pada penelitian ini peralatan yang digunakan meliputi Personal Computer berisi software YMEC (Yoshimasa Electronic) berfungsi sebagai pengolah data tingkat tekanan bunyi yang juga berisi generator(sumber bunyi), mikrofon, amplifier, speaker, perangkat lunak Matlab R2007b, tripod. Ruang uji penelitian ditunjukkan Gambar 2.

Dari hasil data pengukuran yang diperoleh, kemudian dapat dilakukan perhitungan besarnya koefisien difusi digunakan persamaan:

$$
d_{\circ}=\frac{\left(\sum_{i=1}^{n} 10^{\frac{L_{i}}{10}}\right)^{2}-\sum_{i=1}^{n}\left(10^{\frac{L_{i}}{10}}\right)^{2}}{(n-1) \sum_{i=1}^{n}\left(10^{\frac{L_{i}}{10}}\right)^{2}}
$$

dengan $\mathrm{L}_{i}=$ tekanan bunyi pantul difuser pada titik ke $\mathrm{i}(\mathrm{dB})$, $\mathrm{n}=$ jumlah receiver (pengambilan data SPL dalam beberapa sudut ukur, rentang sudut pengukuran dari $0^{\circ}-180^{\circ}$ dan pengambilan data dilakukan pada sudut kelipatan $10^{\circ}$ ).

Data yang diperoleh disini adalah data SPL (dB), dengan rumusan:

$$
\begin{aligned}
L_{i} & =L_{d}-L_{t d} \\
L_{d} & =10 \log \left(\frac{P_{d}^{2}}{P_{a c}^{2}}\right) \\
L_{t d} & =10 \log \left(\frac{P_{t d}^{2}}{P_{a c}^{2}}\right)
\end{aligned}
$$

dengan $\mathrm{L}_{i}=$ tekanan bunyi pantul difuser pada titik ke $\mathrm{i}(\mathrm{dB})$, $\mathrm{L}_{d}=$ tingkat tekanan bunyi SPL dengan difuser $(\mathrm{dB}), \mathrm{L}_{t d}=$ tingkat tekanan bunyi SPL tanpa difuser $(\mathrm{dB}), \mathrm{P}_{a c}^{2}=$ tekanan acuan $\left(2 \times 10^{-5} \mathrm{~Pa}\right), \mathrm{P}^{2}$ adalah antilog dari $\mathrm{L}$.

\section{HASIL DAN PEMBAHASAN}

Dalam pengukuran SPL suatu ruangan, sangat penting terlebih dahulu mengukur besarnya tingkat bising sekitar (background noise). Adapun data tingkat bising sekitar yang diperoleh ketika pengukuran yaitu dapat dilihat pada Tabel I.

Setelah melakukan pengukuran di ruang uji, didapatkan data SPL pada masing-masing titik ukur ketika pengukuran dengan difuser 2D dan tanpa difuser. Hasil SPL selanjutnya 


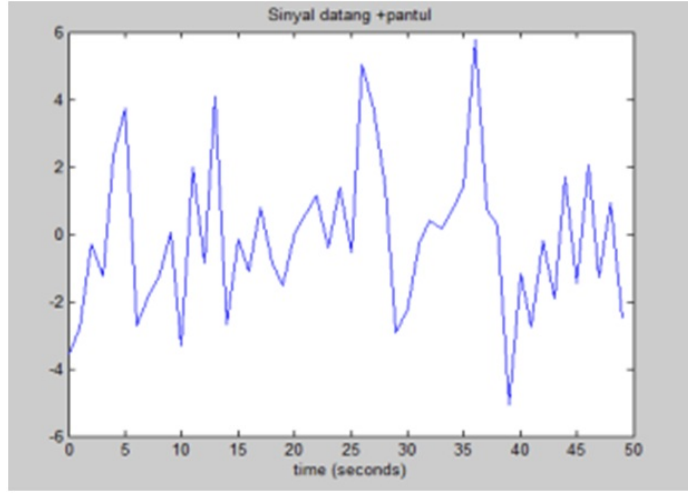

(a)

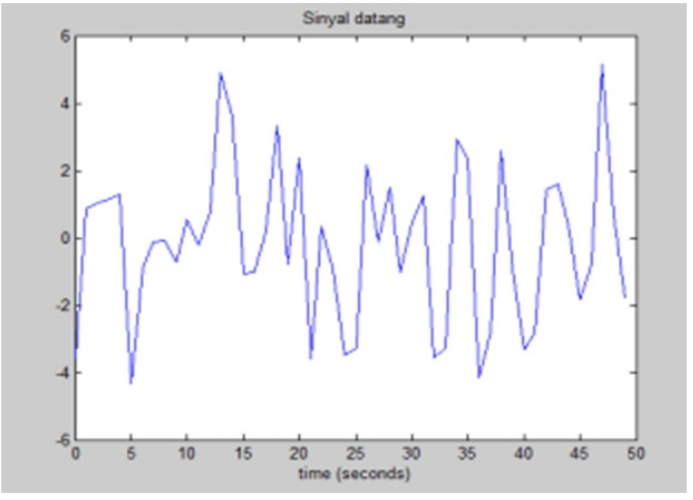

(b)

Gambar 3: Kurva sinyal dalam domain waktu: (a) bunyi datang + pantul; (b) bunyi datang, di ruang semianechoic Fisika Fmipa ITS dengan jarak $70 \mathrm{~cm}$ dari difuser kayu 2D.

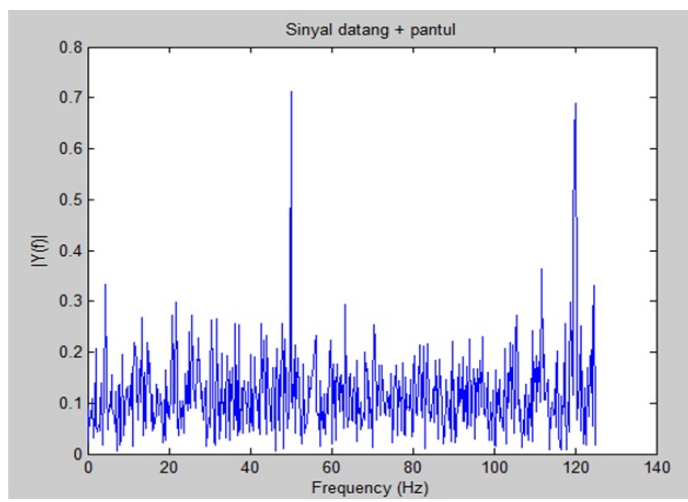

(a)

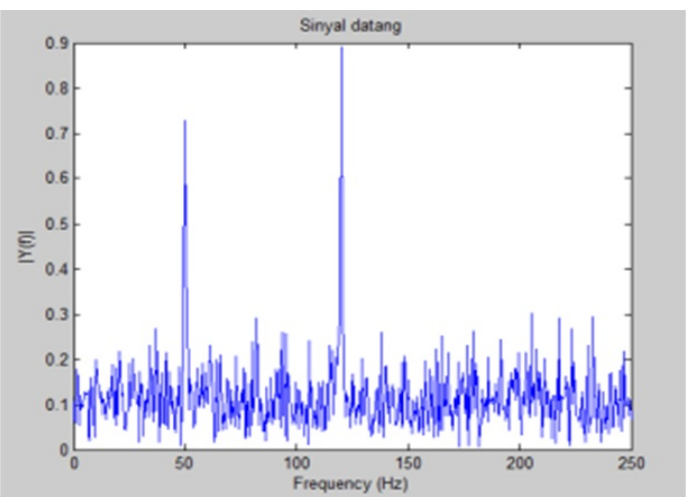

(b)

Gambar 4: Kurva sinyal dalam domain frekuensi (FFT): (a) bunyi datang + pantul; (b) bunyi datang, di ruang semianechoic Fisika Fmipa ITS dengan jarak $70 \mathrm{~cm}$ dari difuser kayu 2D.

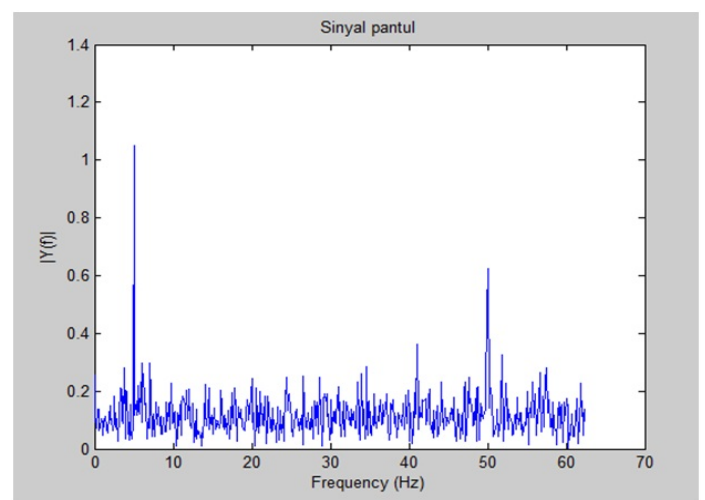

Gambar 5: Kurva sinyal hasil pemisahan bunyi pantul dalam domain frekuensi di ruang semianechoic Fisika Fmipa ITS dengan jarak 70 $\mathrm{cm}$ dari difuser kayu 2D.

digambar kurva sinyal bunyi datang + pantul dan bunyi datang dalam domain waktu, seperti ditunjukkan Gambar 3.

Setelah didapatkan kurva pada Gambar 3 dapat dilihat bahwa kurva sinyal dalam domain waktu bunyi datang dan

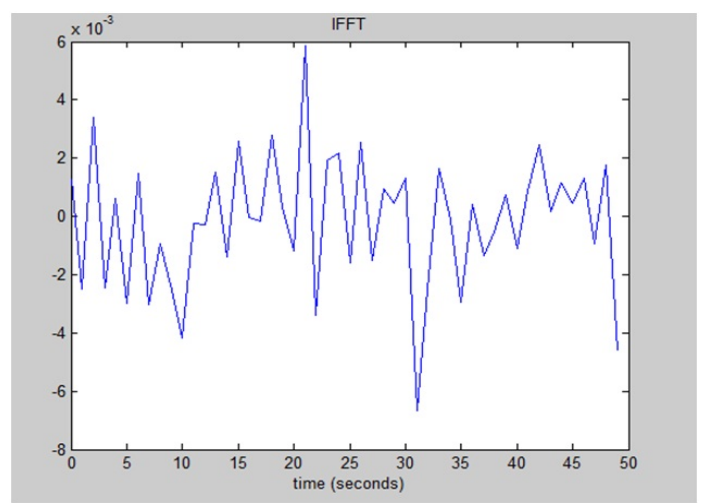

Gambar 6: Kurva sinyal hasil pemisahan bunyi pantul dalam domain waktu di ruang semianechoic Fisika Fmipa ITS dengan jarak $70 \mathrm{~cm}$ dari difuser kayu 2D.

bunyi datang + pantul belum dapat dianalisa sehingga langkah selanjutnya yaitu mengubah kurva bunyi datang + pantul dan bunyi datang dari domain waktu ke domain frekuensi (FFT) (Lihat Gambar 4). Hal ini dilakukan agar mendapatkan bunyi 


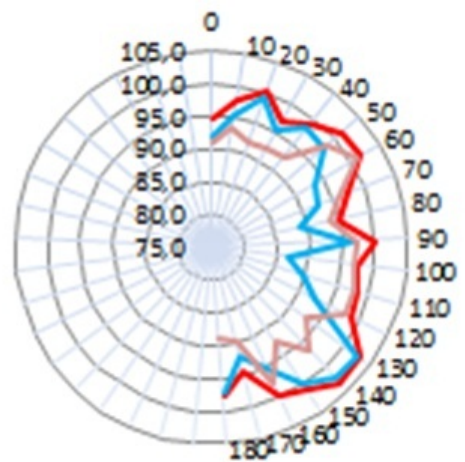

(1)

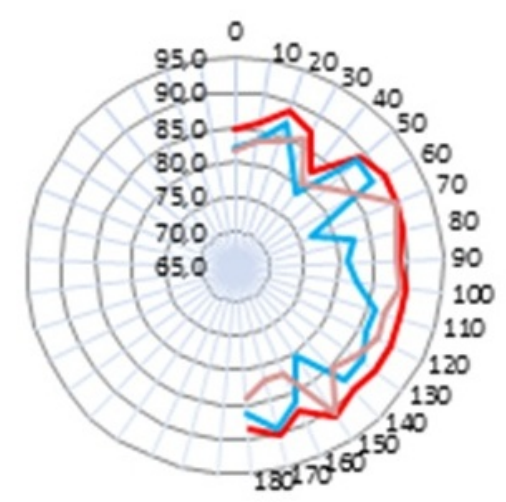

(1)

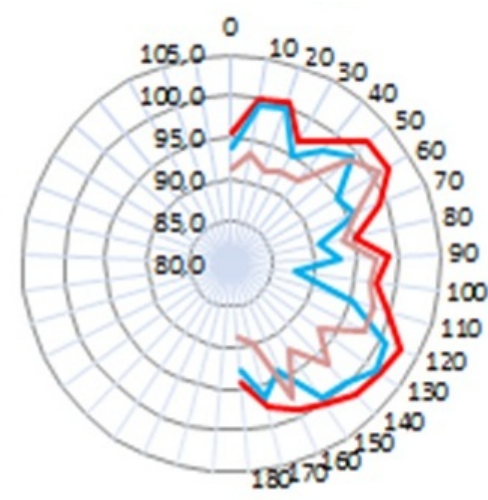

(2)

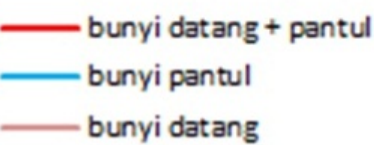

(a) $500 \mathrm{~Hz}$

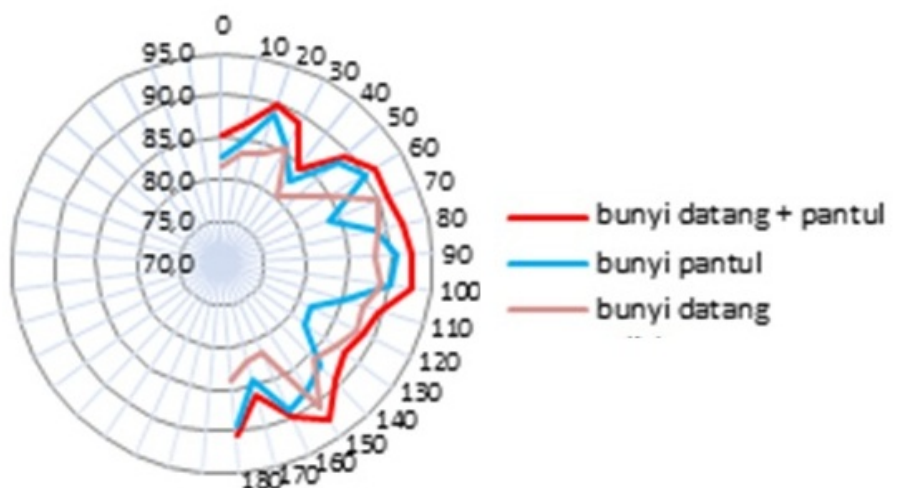

(2)

(b) $2000 \mathrm{~Hz}$

Gambar 7: Grafik polar (1) difuser kayu 2D; (2) difuser bubur kertas 2D; yang diperoleh di Ruang Laboratoriun Akustik Fisika ITS pada jarak mikrofon $70 \mathrm{~cm}$ dari difuser dengan variasi frekuensi.

TABEL I: Data tingkat bising sekitar (background noise).

\begin{tabular}{cc}
\hline \hline Frekuensi $(\mathrm{Hz})$ & Tingkat bising sekitar $(\mathrm{dB})$ \\
\hline & \\
125 & $42,9-37,9$ \\
250 & $37,8-30,3$ \\
500 & $24,7-20,8$ \\
1000 & $20,1-16,7$ \\
2000 & $14,6-12,3$ \\
4000 & $13,6-12,2$ \\
\hline \hline
\end{tabular}

pantul.

Setelah didapatkan kurva hasil windowing dalam domain frekuensi, maka dapat dilakukan pemisahan sinyal dengan cara mengurangi hasil pada kurva sinyal datang+pantul dengan sinyal datang sehingga didapatkan kurva sinyal pantul saja seperti pada Gambar 5.

Sinyal bunyi pantul pada Gambar 5 masih dalam domain frekuensi. Untuk mendapatkan nilai tekanan yang terjadi saat bunyi pantul maka perlu diubah kembali ke dalam domain
TABEL II: Hasil perhitungan koefisien difusi.

\begin{tabular}{cc}
\hline \hline \multicolumn{2}{c}{ K o e f i s i e n D i f u s i } \\
\hline Difuser Kayu 2D Difuser Bubur Kertas 2D \\
\hline $0,312 \pm 0,008 \quad 0,319 \pm 0,007$ \\
\hline \hline
\end{tabular}

waktu (IFFT), dan hasilnya dapat dilihat pada Gambar 6.

Sinyal bunyi pantul yang didapatkan pada Gambar 6 masih dinyatakan dalam besarap $\mathrm{P}_{2}$ sehingga perlu diubah dalam bentuk $\mathrm{L}_{i}$. Salah satu karakter difuser ditunjukkan oleh besarnya koefisien difusinya. Dengan menggunakan metode separasi sinyal telah ditunjukkan langkah memperoleh besarnya SPL bunyi yang dipantulkan (Li). Dengan menggunakan Pers. 3 - 4 didapatkan hasil perhitungan besarnya d0 difuser kayu 2D dapat diperoleh. Hasil semua perhitungan koefisien difusi difuer kayu 2D dan difuser bubur kertas 2D pada jarak pengukuran $70 \mathrm{~cm}$ dari difuser yang dilakukan di ruang semianechoic Laboratorium Akustik Fisika ITS, ditunjukkan Tabel II.

Berdasarkan hasil koefisien difusi yang diperoleh di atas, 
dapat disimpulkan bahwa difuser bubur kertas 2D sama dengan difuser kayu 2D yaitu 0,3 artinya koefisien difusi tidak dipengaruhi oleh jenis bahan difuser yang digunakan. lebih menghamburkan bunyi. Dengan selisih koefisien difuser hanya 0,007 mengartikan bahwa dengan bahan yang berbeda dan bentuk yang sama, nilai koefisien difuser tidak terpengaruh besar oleh bahan difuser.

Untuk lebih jelasnya sebagai contoh hasil pengukuran antara bunyi datang, bunyi datang + bunyi pantul dan perhitungan bunyi pantul dapat dilihat dari grafik polar seperti ditunjukkan Gambar 7.

Pada grafik polar yang ditunjukkan pada Gambar 7 pola hamburan yang hampir sama. Pola hamburan yang hampir sama menunjukkan nilai koefisien difusi difuser yang sama yaitu difuser bubur kertas $2 \mathrm{D}(0,3190,007)$ dan difuser kayu $2 \mathrm{D}(0,312 \pm 0,008)$. Namun pada grafik menunjukkan bentuk fluktuasi pola hamburan antara frekuensi menunjukkan nilai SPL pada difuser kayu lebih besar dari pada difuser bubur kertas 2D, hal ini dikarenakan koefisien absorbsi bubur kertas lebih besar jika dibandingkan dengan kayu.

Dari penelitian yang dilakukan, dapat diketahui bahwa variasi bahan yang digunakan untuk difuser tidak mempengaruhi besarnya nilai koefisien difusi, melainkan dapat mengetahui bahan tersebut bisa digunakan dengan ruang berkriteria ter- tentu. Seperti halnya difuser 2D bahan bubur kertas dengan kriteria berupa daya absorber yang lebih besar dari pada daya pantulan dapat digunakan sebagai peredam sedangkan untuk difuser 2D bahan kayu dengan kriteria daya pantul yang lebih besar dapat digunakan sebagai pemantul bunyi untuk suatu ruangan dengan kriteria tertentu. Sehingga diharapkan untuk penelitian selanjutnya selain menentukan besarnya koefisien difusi juga menentukan koefisien hamburan(scatering) yang ada kaitannya dengan koefissien absorbsi bunyi.

\section{SIMPULAN}

Besarnya koefisien diffuser kayu dan bubur kertas 2D memilliki nilai yang sama, yaitu $0,312 \pm 0,008$ untuk diffuser kayu 2D dan 0,319 $\pm 0,007$ untuk diffuser bubur kertas 2D. Pola hamburan yang terjadi pada difuser kayu dan bubur kertas pada seluruh frekuensi hampir sama hanya berbeda tingkat tekanan bunyi yang dihamburkan. Difuser bubur kertas yang dibuat bersifat difsorber yaitu sebagai pendiffus bunyi sekaligus sebagai absorbsi bunyi. Besarnya koefisien difusi hanya bergantung pada bentuk dimensinya, namun tidak bergantung dengan jenis bahan.
[1] P. D'Antonio, T.J. Cox, Acoustic absorbers and difuser : theory, design and application (Spoon Press: London 2004).

[2] F. Kurniawan F., Pengaruh Variasi Jenis Bahan Terhadap Pola Hamburan Pada Difuser MLS (Maximum Length Sequences) dan QRD (Duadratic Residue Diffuser), Tugas Akhir, ITS-Surabaya, 2013.

[3] S. Indrawati, Karakterisasi Difuser dengan Menggunakan Model
Separasi Sinyal Akustik, ITS-Surabaya, 2011.

[4] F.A. Everest, K.C. Pohlmann, Master Handbook of Acoustic (McGraw-Hill, New York, 2009).

[5] H.W. Strube, J. Acoust. Soc. Am., 70, 633 (1981).

[6] J.G. Proakis, Manolakis, Digital Sinyal Processing (edisi 4, Prentice Hall, New Jersey, 2007). 